\title{
Optical and Micro-structural Properties of GaN Nanowires by Ammoniating $\mathrm{Ga}_{2} \mathrm{O}_{3} / \mathrm{Nb}$ Films
}

\author{
Zhuang Huizhao, Li Baoli, Wang Dexiao, Shen Jiabing, \\ Zhang Shiying, Xue Chengshan
}

Shandong Normal University, Ji'nan 250014, China

\begin{abstract}
Single-crystalline $\mathrm{GaN}$ nanowires have been synthesized on $\mathrm{Si}(111)$ substrates by magnetron sputtering through ammoniating the $\mathrm{Ga}_{2} \mathrm{O}_{3} / \mathrm{Nb}$ films at $900{ }^{\circ} \mathrm{C}$ in a quartz tube. The as-prepared nanowires are confirmed as single crystalline GaN with wurtzite structure by X-ray diffraction (XRD), selected-area electron diffraction (SAED) and high-resolution transmission electron microscopy (HRTEM). Transmission electron microscopy (TEM) shows that the GaN nanowires are straight and smooth, and possess the diameters of about $50 \mathrm{~nm}$ and lengths up to several microns. When excited by $325 \mathrm{~nm}$ helium-cadmium (He-Cd) laser light at room temperature, the GaN nanowires only have a strong ultraviolet luminescence peak located at $367 \mathrm{~nm}$, owing to GaN band-edge emission. Finally, the growth mechanism of GaN nanowires is discussed briefly.
\end{abstract}

Key words: nanowires; ammoniating; GaN

GaN, a wide and direct band gap semiconductor $(3.4 \mathrm{eV}$ at room temperature), is an ideal material for the fabrication of ultraviolet, blue light-emitting diodes and high-power/high- temperature electronics devices ${ }^{[1]}$. Its one-dimensional 1D nanostructure has been synthesized for potential applications in field emission devices ${ }^{[2,3]}$. In the last few years, the significant progress in GaN nanowire growth ${ }^{[4,5]}$, and individual device fabrication $^{[6,7]}$ was made. Since Fan and co-workers first synthesized the $\mathrm{GaN}$ nanorods through a carbon nanotube-confined reaction of $\mathrm{Ga} / \mathrm{Ga}_{2} \mathrm{O}_{3}$ mixture with $\mathrm{NH}_{3}{ }^{[8]}$, many efforts have been dedicated to developing different techniques for preparing $\mathrm{GaN}$ nanorods. The popular methods include carbon nanotube-confined reaction ${ }^{[8]}$ or template-induced growth $^{[9]}$, metal-catalyzed growth ${ }^{[10]}$, and direct reaction of metal Ga with $\mathrm{NH}_{3}{ }^{[11,12]}$. In the last few years, our group developed a novel method for synthesizing one-dimen- sional $\mathrm{GaN}$ materials through ammoniating $\mathrm{Ga}_{2} \mathrm{O}_{3}$ films ${ }^{[13]}, \mathrm{Ga}_{2} \mathrm{O}_{3} / \mathrm{SiC}$ films ${ }^{[14]}$, $\mathrm{Ga}_{2} \mathrm{O}_{3} / \mathrm{ZnO}$ films ${ }^{[15]}$ and $\mathrm{Ga}_{2} \mathrm{O}_{3} / \mathrm{MgO}$ films ${ }^{[16]}$, which were deposited by RF magnetron sputtering. However, the yield and the quality of the synthesized GaN nanowires are still to be opti- mized for the application of GaN nanowires to nanoelectronic devices. Up to now, there is lack of the information on $\mathrm{GaN}$ nanowires synthesizing by ammoniating $\mathrm{Ga}_{2} \mathrm{O}_{3}$ films on $\mathrm{Nb}$ layer deposited on $\mathrm{Si}(111)$ substrates. In this paper, we report the successful preparation of $\mathrm{GaN}$ nanowires on $\mathrm{Si}(111)$ substrates through ammoniating $\mathrm{Ga}_{2} \mathrm{O}_{3} / \mathrm{Nb}$ films in flowing ammonia atmosphere at $900{ }^{\circ} \mathrm{C}$ in a quartz tube.

\section{Experimental Procedure}

In our experiment, GaN nanowires were prepared by the reaction of $\mathrm{Ga}_{2} \mathrm{O}_{3}$ films with $\mathrm{NH}_{3}$. The nanowires were prepared by a two-step method. The first step was the process of forming $\mathrm{Nb}$ layer. $\mathrm{Nb}$ films were deposited on $\mathrm{Si}(111)$ substrates by the progress of direct current (D.C.) sputtering with JCK-500A magnetron sputtering system. The conditions of sputtering were as follows: the background pressure was $1.2 \times 10^{-3} \mathrm{~Pa}$; the distance between targets and substrates was $8 \mathrm{~cm}$; the pressure of $\mathrm{Ar}$ ( $\geq 99.99 \%$ ) was $2 \mathrm{~Pa}$; the output voltage of WLY steady current device was $260 \mathrm{~V}$ and the output current was $160 \mathrm{~mA}$. After $10 \mathrm{~s}$, $\mathrm{Nb}$ films with a thickness of about $10 \mathrm{~nm}$ were obtained.

Received date: April 10, 2008; Revised manuscript received date: June 7, 2008

Foundation item: National Natural Science Foundation of China(Grant No90301002) and Supported by the Key Research Program of the National Natural Science Foundation of China(Grant No 90201025)

Biography: Zhuang Huizhao, Professor, Institute of Semiconductors, Shandong Normal University, Ji'nan 250014, P. R. China, Tel: 0086-531-86182624, E-mail: zhuanghuizhao@sdnu.edu.cn

Copyright (C) 2009, Northwest Institute for Nonferrous Metal Research. Published by Elsevier BV. All rights reserved. 
The second step was to deposit $\mathrm{Ga}_{2} \mathrm{O}_{3}$ films and synthesize $\mathrm{GaN}$ nanowires. $\mathrm{Ga}_{2} \mathrm{O}_{3}$ was deposited on the $\mathrm{Nb}$ layer on $\mathrm{Si}(111)$ substrates by radio frequency (r.f.) magnetron sputtering. Compared with the first step, the different conditions were as follows: the sputtering power was fixed at $150 \mathrm{~W}$ and the frequency was $13.56 \mathrm{MHz}$. After $90 \mathrm{~min}, \mathrm{Ga}_{2} \mathrm{O}_{3}$ films with a thickness of about $500 \mathrm{~nm}$ were obtained. Then the samples were placed into the reaction system. $\mathrm{N}_{2}$ was introduced into the system for $5 \mathrm{~min}$ to expel air. Subsequently, $\mathrm{NH}_{3}$ $(\geq 99.999 \%$ ) with a flux of $500 \mathrm{~mL} / \mathrm{min}$ was introduced into the system. The reaction lasted for $10 \mathrm{~min}$ at $900{ }^{\circ} \mathrm{C}$.

A RigakuD/max-rB X-ray diffraction (XRD) meter with a $\mathrm{Cu} \mathrm{K} \alpha$ line was used to examine the crystalline structure. The microstructure and surface morphology of the $\mathrm{GaN}$ nanowires were observed by means of a Hitachi H-800 transmission electron microscope (TEM) and a Philips TECNAIF30 field-emission transmission electron microscope (FETEM). Fourier transform infrared spectroscopy (FTIR, TEN-SOR27) was used to examine the composition information of the samples. Room-temperature photoluminescence (PL) measurements of the obtained GaN nanowires were carried out by a He-Cd laser (excitation wavelength $=325 \mathrm{~nm}$ ).

\section{Results and Discussion}

\subsection{XRD analysis}

Fig. 1 shows the XRD pattern of the as-synthesized GaN nanowires. Peaks were found at $32.39^{\circ}, 34.59^{\circ}, 36.79^{\circ}$ and $48.12^{\circ}$ in correspondence with the hexagonal wurtzite GaN. They are due to the (100), (002), (101) and (102) diffraction peaks of hexagonal GaN, respectively. All refraction peaks can be indexed to a hexagonal wurtzite $\mathrm{GaN}$ phase with the lattice constants $a_{0}=0.3190 \mathrm{~nm}$ and $c_{0}=0.5189 \mathrm{~nm}$, which are in good agreement with the values reported for $\mathrm{GaN}^{[17]}$. The strongest (101) peak of GaN mainly accords with bulk GaN in the XRD pattern ${ }^{[18]}$. No any other diffraction peaks are observed in any of our samples, indicating that the sample is predominantly polycrystalline hexagonal wurtzite $\mathrm{GaN}$ phase with high purity. The sharp diffraction peaks also reveal the high crystallization of the samples prepared in this way.

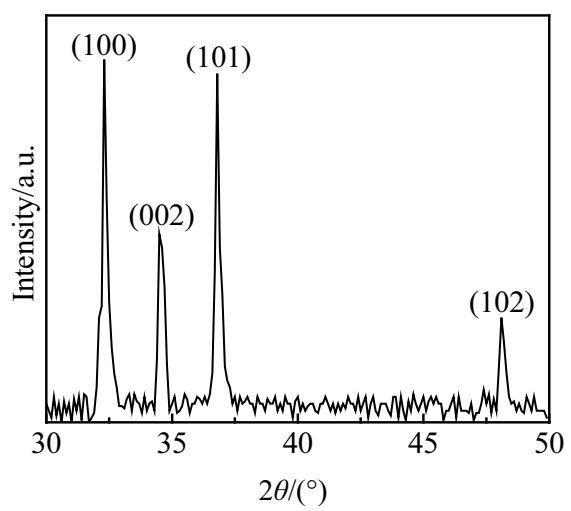

Fig.1 XRD pattern of the nanowires obtained at $900{ }^{\circ} \mathrm{C}$

\subsection{TEM analysis}

The morphology of the sample was characterized by TEM. Fig.2a shows the typical TEM image of the GaN nanowires ammoniated at $900{ }^{\circ} \mathrm{C}$ with high density, and we can see the nanowires cross each other and randomly distribute on the whole surface. These nanowires are straight and smooth with diameters of about $50 \mathrm{~nm}$ and lengths up to several microns by statistical survey. And Fig.2b is a TEM image for a single $\mathrm{GaN}$ nanowire with a diameter of about $50 \mathrm{~nm}$. It is straight and has a fairly clean surface without any particles.

\subsection{HRTEM analysis}

Fig. 3 shows the HRTEM lattice image of a single nanowire and the corresponding selected area electron diffraction (SAED) pattern of the single nanowire. The lattice is very perfect and its orientation is clear and uniform. In the image, the distance between the two stripes is $0.275 \mathrm{~nm}$, which is corresponding to the distance between two (100) planes. The HRTEM image reveals that the normal of the nanowire is [001] orientation. The insert in the upper-right-corner of Fig. 3 is the selected area electron diffraction (SAED) pattern of the nanowire sample, which can be indexed to the diffraction of wurtzite GaN crystal along the [021] direction. It is also confirmed that the nanowires are single crystalline $\mathrm{GaN}$.

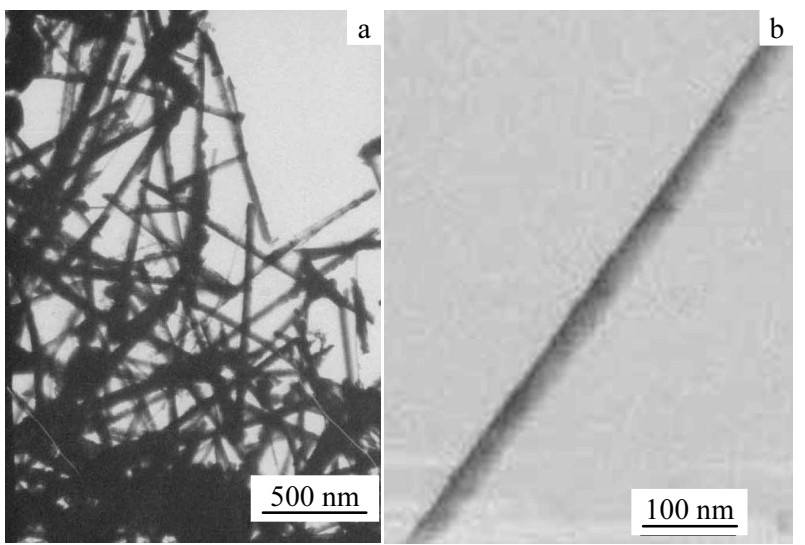

Fig.2 (a) Typical TEM image of the GaN nanowires. (b) TEM image of a single $\mathrm{GaN}$ nanowire

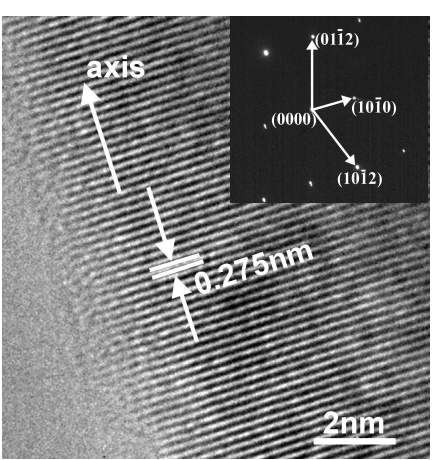

Fig.3 HRTEM lattice image of an individual GaN nanowire and the insert is the SAED pattern 


\subsection{XPS analysis}

The XPS was employed to investigate the chemical composition of the sample. Fig. 4 shows the XPS for the GaN synthesized at the ammoniating temperature of $900{ }^{\circ} \mathrm{C}$. Ga $3 \mathrm{~d}, \mathrm{Ga}$ 3p, Ga3s, Ga LMM Auger peak, C1s, N1s and O1s core level peaks were selected for the investigation in the binding energy between 0 and $600 \mathrm{eV}$. The peak of N1s is observed at 397.8 eV in Fig.4b. The width and slight asymmetry of the N1s peak can be attributed to the presence of chemisorbed nitrogen along with nitrogen in $\mathrm{GaN}^{[19]}$. Besides, no bonding formation between $\mathrm{Ga}$ and $\mathrm{O}$ could be attributed to that no satellite peak corresponding to $\mathrm{Ga}_{2} \mathrm{O}_{3}{ }^{[20]}$ shown by Ga3d spectrum. In Fig.4c, the measured value of Ga3d peak of the sample centered at $19.9 \mathrm{eV}$ is in good agreement with the published binding energy values of the Ga3d peak at $19.9 \mathrm{eV}$ of compound $\mathrm{GaN}^{[21]}$. The value in this experiment has a positive shift from element gallium with Ga3d peak centered at $18.5 \mathrm{eV}$, indicating that the $\mathrm{Ga}$ atoms in the sample are in the compound state $(\mathrm{GaN})$. $\mathrm{Ga} 2 \mathrm{p}_{3 / 2}$ and $\mathrm{Ga} 2 \mathrm{p}_{1 / 2}$ peaks for the as-grown $\mathrm{GaN}$ nanowires are shown in Fig. $4 d$. The peaks of Ga2 $p_{1 / 2}$ and $\mathrm{Ga} 2 \mathrm{p}_{3 / 2}$ are observed at the binding energies of $1144.9 \mathrm{eV}$ and $1118.1 \mathrm{eV}$, respectively. The result is in agreement with that observed by Paletal $^{[22]}$. The core level of $\mathrm{Ga}$ has a positive shift from elemental Ga. This shift in binding energies of $\mathrm{Ga}$ and $\mathrm{N}$ confirms the bonding between $\mathrm{Ga}$ and $\mathrm{N}$ as well as the absence of elemental gallium. The quantification of the peaks gives the atomic ratio of $\mathrm{Ga} / \mathrm{N}$ close to $1: 1$.

\subsection{PL analysis}

Fig. 5 shows the PL spectrum of GaN nanowires ammoniated at $900{ }^{\circ} \mathrm{C}$. The PL measurement was conducted using a
$325 \mathrm{~nm}$ helium-cadmium (He-Cd) laser as the excitation source. There is only a strong and broad UV light emission peak at $369 \mathrm{~nm}(3.36 \mathrm{eV})$, which is associated with the near-band-edge emission of GaN. Because the as-grown GaN nanowires are too large for quantum confinement effects, and even the diameter of the thinnest $\mathrm{GaN}$ nanowires is much larger than the Bohr exciton radius $(11 \mathrm{~nm})$ of $\mathrm{GaN}^{[23]}$, the UV light emission peak has no blue shift of the bandgap emission compared with the bulk $\mathrm{GaN}^{[24]}$. The GaN nanowires show a very excellent good emission property, which will have a good advantage for applications in laser devices using one-dimensional structures. However, for the further work the PL mechanism of the GaN nanowires is to be investigated.

\subsection{Discussion about growth process of $\mathrm{GaN}$}

In our experiment, there are probably several chemical reactions involved in our approach to synthesize GaN nanowires. $\mathrm{NH}_{3}$ decomposes step by step to $\mathrm{NH}_{2}, \mathrm{NH}$, and $\mathrm{N}$ at the temperatures of above $850{ }^{\circ} \mathrm{C}^{[5]}$. So, $\mathrm{H}_{2}$ can be assumed to present in our system. $\mathrm{Ga}_{2} \mathrm{O}_{3}$ will be reduced to $\mathrm{Ga}_{2} \mathrm{O}$ through the followed reactions ${ }^{[25]}$. The reaction of $\mathrm{Ga}_{2} \mathrm{O}$ with ammonia results in the formation of $\mathrm{GaN}$ crystal nuclei. In the process of ammoniating reaction, the main chemical reaction taking place in our system can be expressed as follows ${ }^{[26]}$ :

$$
\begin{aligned}
& 2 \mathrm{NH}_{3}(\mathrm{~g}) \rightarrow \mathrm{N}_{2}(\mathrm{~g})+3 \mathrm{H}_{2}(\mathrm{~g}) \\
& \mathrm{Ga}_{2} \mathrm{O}_{3}(\mathrm{~s})+2 \mathrm{H}_{2}(\mathrm{~g}) \rightarrow \mathrm{Ga}_{2} \mathrm{O}(\mathrm{g})+2 \mathrm{H}_{2} \mathrm{O}(\mathrm{g}) \\
& \mathrm{Ga}_{2} \mathrm{O}(\mathrm{g})+2 \mathrm{NH}_{3}(\mathrm{~g}) \rightarrow 2 \mathrm{GaN}(\mathrm{s})+2 \mathrm{H}_{2}(\mathrm{~g})+\mathrm{H}_{2} \mathrm{O}(\mathrm{g})
\end{aligned}
$$

There is $\mathrm{SiO}_{2}$ layer on the surface of the substrate before the deposition. When niobium is deposited on oxide supports, such as $\mathrm{SiO}_{2}$, a dispersed niobium oxide surface phase will be formed $^{[27]}$. The surface niobium oxide phase has a pronounced
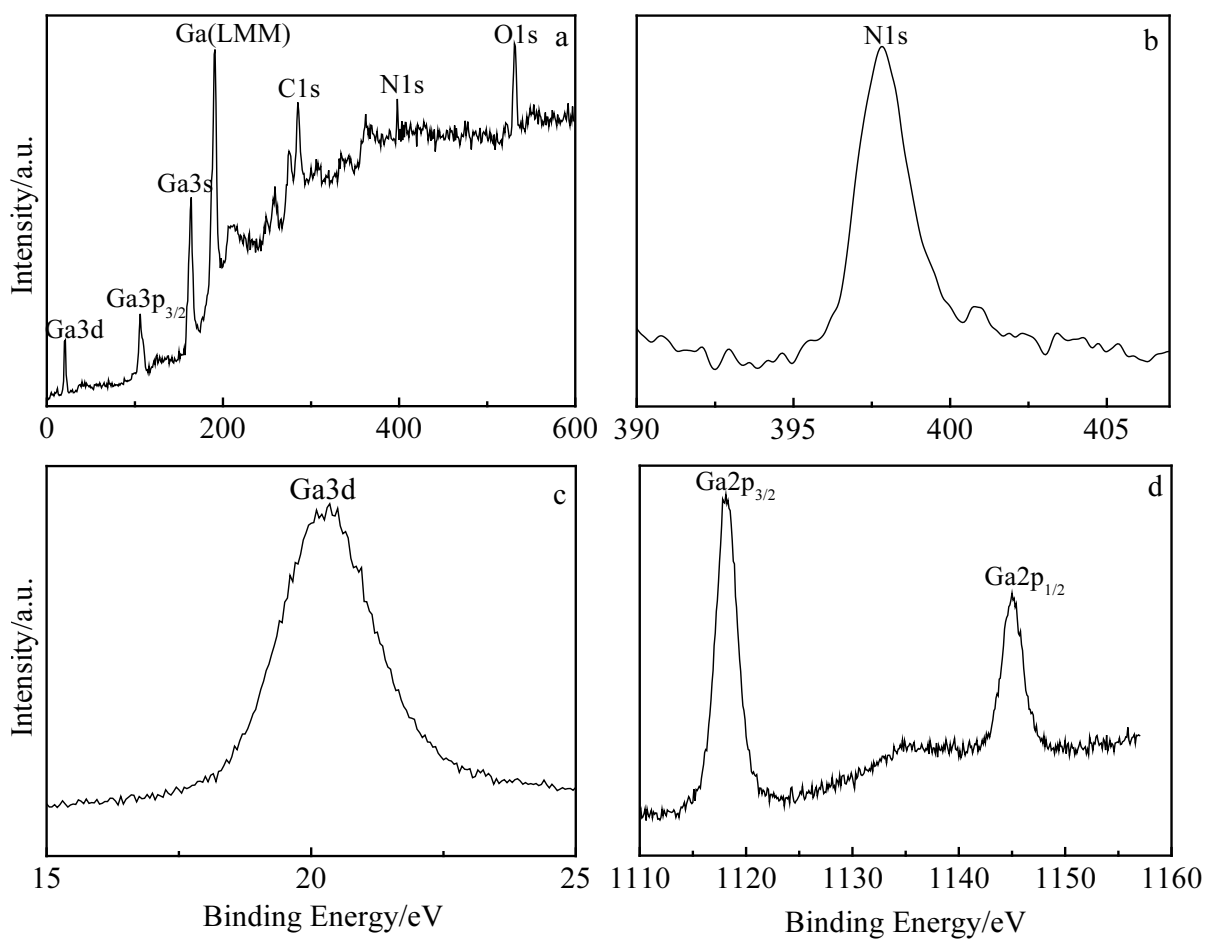

Fig.4 XPS spectra obtained from the sample ammoniated at $900{ }^{\circ} \mathrm{C}$ 


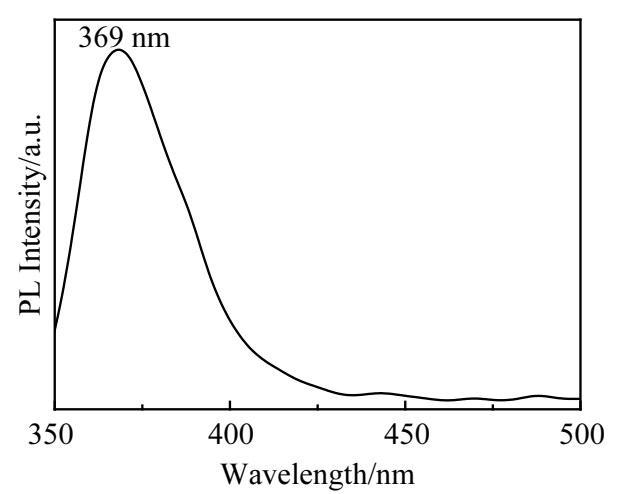

Fig.5 PL spectrum of $\mathrm{GaN}$ nanowires ammoniated at $900{ }^{\circ} \mathrm{C}$

catalysis effect on above-mentioned three chemical reactions and the growth of GaN nanowires. Because of the decomposition of $\mathrm{Ga}_{2} \mathrm{O}_{3}$, parts of dispersed niobium oxide surface phase may leak out on the surface of the substrate. The $\mathrm{Ga}_{2} \mathrm{O}$ vapor evaporates at the reaction temperature and transfers from chemical reactions sites to the substrate, where catalytic reaction takes place. At the same time, atomic nitrogen is produced by the catalytic decomposition of $\mathrm{NH}_{3}$ introduced into the quartz tube. Dissolving into the dispersed niobium oxide surface phase layer, $\mathrm{Nb}-\mathrm{O}-\mathrm{Si}-\mathrm{Ga}-\mathrm{N}$ liquid alloy nanoparticles are thus formed. The $\mathrm{Nb}-\mathrm{O}-\mathrm{Si}-\mathrm{Ga}-\mathrm{N}$ transition alloy maintains a liquid phase while the catalytic reaction proceeds. When the concentration of Ga-N exceeds a saturation point in the liquid phase $\mathrm{Nb}-\mathrm{O}-\mathrm{Si}-\mathrm{Ga}-\mathrm{N}$ alloy droplet, $\mathrm{GaN}$ begins to grow from liquid phase and deposits to form nanowires. Therefore, the $\mathrm{GaN}$ nanowires formed through the catalysts on the substrate gradually increase, as shown in Fig.6. Why is the sign of any metal or alloy droplets not found at the end of the nanorods? Because the nano-sized dispersed niobium oxide surface phase layer (Nb-O-Si layer) has very specific properties ${ }^{[28]}$ on one hand. On the other hand, because of sublimation of $\mathrm{GaN}$, the catalyst particle is displaced to the $\mathrm{Si}$ substrate but this does not impact the overall morphology. In order to identify the catalytic effect of $\mathrm{Nb}$, we also ammoniated a sample where only a $\mathrm{Ga}_{2} \mathrm{O}_{3}$ film was deposited on $\mathrm{Si}$ substrates using the same conditions. As a result, no nanowires were observed. It is proved that $\mathrm{Nb}$ plays an important role in the growth process of $\mathrm{GaN}$ nanowires. It can be seen that the high temperature, ammonia, $\mathrm{Nb}$ layer and $\mathrm{Ga}_{2} \mathrm{O}_{3}$ are crucial in the growth of $\mathrm{GaN}$ nanowires. However, the further function of the $\mathrm{Nb}$ in the growth of $\mathrm{GaN}$ nanowires and more details are under study.

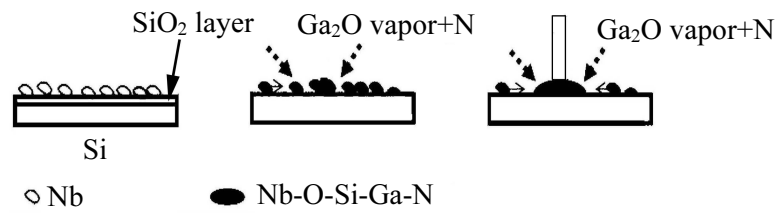

Fig.6 A proposed mechanism for forming the nanowires

\section{Conclusion}

1) GaN nanowires has been synthesized on $\mathrm{Si}$ (111) substrates through ammoniating of $\mathrm{Ga}_{2} \mathrm{O}_{3} / \mathrm{Nb}$ films in flowing ammonia atmosphere at $900{ }^{\circ} \mathrm{C}$ in quatz tube.

2) The nanowires demonstrate intensive room temperature UV emission, which promises valuable application of the prepared GaN nanwires in optical devices.

\section{References}

1 Nakamura S, Pearton S, Fasol G. The Blue Laser Diode[M]. Berlin: The Complete Story Springer, 2000: 237

2 Shi S C, Chen C F, Chattopadhyay S et al. Appl Phys Lett[J], 2005, 87: 73109

3 Lan Z H, Wang W M, Sun C L et al. J Cryst Growth[J], 2004, 269: 87

4 Peng H Y, Zhou X T, Wang N et al. Chem Phys Lett[J], 2000, 327: 263

5 He M, Minus I, Zhou P et al. Appl Phys Lett[J]. 2000, 77: 3731

6 Cha H Y, Wu H, Chandrashekhar M et al. Nanotechnology[J], 2006, 17: 1264

7 Motayed A, Davydov A V, Vaudin M D et al. J Appl Phys[J], 2006, 100: 24306

8 Han W, Fan S, Li Q et al. Science[J], 1997, 277: 1287

9 Cheng G S, Chen S H, Zhu X G. Mater Sci Eng A[J], 2000, 286: 165

10 Bae S Y, Seo H W, Park J et al. Appl Phys Lett[J], 2003, 82: 4564

11 Zhao L X, Meng G W, Peng X.S et al. J Cryst Growth[J], 2002, 235: 124

12 Zhao L X, Meng G W, Peng X S et al. Appl Phys A[J], 2002, 74: 587

13 Yang L, Xue C, Wang C et al. Nanotechnology[J], 2003, 14: 50

14 Dong Z, Xue C, Zhuang H et al. Physica, E Low-Dimens Syst Nanostruct[J]. 2005, 27: 32.

15 Shoubin X, Huizhao Z, Chengshan X et al. Appl Phys A[J], 2007, 00: 1

16 Ai Y, Xue C. Mater Lett[J], 2007, 61(13): 2833

17 Perlin P, Jauberthiecarillon C, Itie J et al. Phys Rev B[J], 1992, 45: 83

18 Dong Z, Xue C, Zhuang H et al. Phys E[J], 2005, 27: 32

19 Nahlah E, Srinivasa R S, Major S. Thin Solid Films[J], 1998, 333 : 9

20 Pal S, Sugino T. Appl Surf Sci[J]. 2001, 161: 263

21 Zhang C G, Chen W D, Bian L F et al. Appl Surf Sci[J], 2006, 252: 2153

22 Pal S, Mahapatra R, Ray S K et al. Thin Solid Films[J], 2003, 425: 20

23 Ridley B K. Quantum process in Semiconductors[M]. Oxford: Clarendon, 1982: 62

24 Monemar B. Phys Rev B[J], 1974, 10: 676

25 Butt D, Park P Y, Taylor T N. J Nucl Mater[J], 1999, 264: 71

26 Li B L, Zhuang H Z, Xue C S et al. J Alloy Compds[J]. 2008, 448: 368 
27 Tither G. Progress in Niobium Markets and Technology 19812001[M]. Indianapolis: TMS, 2001: 1
28 Ziolek M. Catalysis Today[J], 2003, 78: 47

\title{
氨化 $\mathrm{Ga}_{2} \mathrm{O}_{3} / \mathrm{Nb}$ 膜制备的 $\mathrm{GaN}$ 纳米线的光学和微观结构特性的研究
}

\author{
庄惠照, 李保理, 王德晓, 申加兵, 张士英, 薛成山 \\ (山东师范大学, 山东 济南 250014)
}

\begin{abstract}
摘 要: 采用射频磁控娍射技术在硅祄底上制备 $\mathrm{Ga}_{2} \mathrm{O}_{3} / \mathrm{Nb}$ 薄膜, 然后在 $900{ }^{\circ} \mathrm{C}$ 下于流动的氨气中进行氨化制备 $\mathrm{GaN}$ 纳米线。用 $\mathrm{X}$ 射 线衍射(XRD)、透射电子显微镜(TEM)和高分辨透射电子显微镜详细分析了 $\mathrm{GaN}$ 纳米线的结构和形貌。结果表明: 采用此方法得到的 $\mathrm{GaN}$ 纳米线有直的形态和光滑的表面, 其纳米线的直径大约 $50 \mathrm{~nm}$, 纳米线的长约几个微米。室温下以 $325 \mathrm{~nm}$ 波长的光激发样品表面, 只显示出一个位于 $367 \mathrm{~nm}$ 的很强的紫外发光峰。最后, 简单讨论了 GaN 纳米线的生长机制。
\end{abstract}

关键词: 纳米线; 氨化; $\mathrm{GaN}$

作者简介: 庄惠照, 女, 1954 年生, 教授, 山东师范大学半导体研究所, 山东 济南 250014, 电话: 0531-86182624, E-mail: zhuanghuizhao@sdnu.edu.cn 